Published in Kahlos M., Koskinen, H.J. \& Palmén R. (eds) Recognition and Religion. Contemporary and Historical Perspectives. London: Routledge. ISBN 978-036-7133-59-7. 2019.

https://doi.org/10.4324/9780429026089

\title{
On the Natural Basis and Ecological Limits of Recognition
}

Arto Laitinen (University of Tampere)

Teea Kortetmäki (University of Jyväskylä)

Abstract: In this chapter, we will discuss the idea that social recognition requires natural resources, and examine its natural, ecological, or environmental aspects. We argue against a view, which would conceptualize social recognition (respect, esteem, trust etc) as conceptually and ontologically independent of its natural basis, which is captured nicely in Richard Sennett's question "Unlike food, respect costs nothing. Why, then should it be in short supply?" We first examine the way in which recognition was materially mediated in Hegel's dialectics of Master and Slave, and then proceed to analyze in more detail what mutual recognition is and in what sense it requires natural resources. It turns out that different forms of recognition are very deeply rooted in material redistribution, and satisfactory relations of recognition in a "society of equals" may require very radical global redistribution. We then raise the stakes by connecting recognition not only with social justice but environmental and ecological justice. We conclude by bringing up the notion of planetary limits.

\section{1. “Unlike food, respect costs nothing. Why, then should it be in short supply?”}

\subsection{Sennett's slogan vs. Hegel's Master and Slave}

Richard Sennett has asked: "Unlike food, respect costs nothing. Why, then should it be in short supply?”. The question is important as such, as there certainly are mechanisms that prevent us from giving each other due recognition when we could materially or economically afford it. ${ }^{1}$ There may be psychological and existential "costs" such as having to admit one's own vulnerability and dependence, and there may be human tendencies not to make any such admissions. We will not focus on such “costs” here.

The idea that "respect costs nothing" expresses a view that social recognition (respect, esteem, trust etc) is conceptually and ontologically independent of its natural or material basis. It is a rather disembodied, unencumbered view of recognition, and we wish to contest it here.

Hegel's famous dialectic of the master and the slave communicates a vivid image of the material basis of recognition: in a struggle of life and death, it comes apparent that a dead person cannot give recognition. ${ }^{2}$ Mutual recognition costs at least as much as keeping someone alive. Of course, if the other already has plenty of resources, it may not cost in practice anything for me to form a relationship of mutual recognition - which creates the image that it costs nothing.

Hegel further notes that the relationship between the master and the slave is materially mediated: the master holds the slave in chains, and the slave works on the material environment for the master. ${ }^{3}$ There are theories of recognition that have insightfully stressed this natural and embodied basis of recognition, drawing on Hegel (Deranty 2009, Testa 2009). Let us approach this in two steps: by asking what recognition is $(1.2,1.3)$, and then by asking what direct and indirect ways

\footnotetext{
$1 \quad$ See e.g. Ikäheimo, 2014.

$2 \quad$ Hegel 1977 [1807]

$3 \quad$ Orlando Patterson (1982) in his classic "Slavery and Social Death” points out that historically speaking concerning real slaves work need not have been the main motivation behind slavery. Slaves have not always worked, as sometimes they have been more like status symbols for the slaveowners
} 
there are in which recognition requires material resources (1.4).

\subsection{What is recognition in the relevant sense? The role of adequate regard and mutuality}

It is often noted that recognition in the relevant sense goes beyond mere "identification" (see Laitinen 2002, Ikäheimo 2002, Ikäheimo \& Laitinen 2007, Ricoeur 2005). It can further be noted that paradigmatic parties in relations of mutual recognition are persons, whose self-relations depend on getting recognition from each other. The relationship of mutual recognition between persons is different from a person merely "acknowledging” the value of something, or the validity of principles: values and principles do not have a relation-to-self and cannot be offended by misrecognition. (Laitinen 2002, Ikäheimo 2002, Ikäheimo \& Laitinen 2007). Thus, recognition in then relevant sense seems to be different from such acknowledgement of normative entities. What is it then?

There are two ways one can go there: either define recognizing in the relevant sense as a special kind of "personifying" attitude (see Ikäheimo 2014), or see recognizing persons as a kind of normative acknowledgement: acknowledging the evaluative significance of the relevant features (Laitinen 2010). What is special about the recognition of persons in the latter views is not located in the nature of the "personifying" recognitive attitude, but in the fact that it is responsiveness to persons, who have features that other entities do not have, and who are capable of mutual relationships that other entities are not.

There is a consideration that speaks for defining the recognition of persons in such a way that such "recognizing" can also concern non-persons, and another consideration that speaks against such a definition. These can be called the "adequate regard"-insight and "mutuality"-insight (Laitinen 2010).

Adequate regard-insight starts from experiences of misrecognition: what do people want when they want to be recognized? It is not merely that they want to be noticed or identified or classified as persons, or persons of this or that type, but they want that they are taken and treated adequately in light of what they are. Such adequate regard for persons is responsiveness to their evaluatively relevant features (which of course need to be noticed, but noticing them is not enough). In that respect, similar responsiveness and regard can concern non-persons: it is a matter of the agent being responsive to the evaluatively relevant features of whatever they deal with. In that sense, then, for example valuing nature non-instrumentally is a matter of adequate regard and "recognition" of nature (it is adequate assuming nature has non-instrumental value).

Another insight would stress that persons experience being recognized, and getting recognition can affect their relations to self. In experiencing "getting recognition" one at the same time gives recognition: recognizes the recognizer as recognizer. Only recognizers can have such experiences of getting recognition. This "mutuality-insight" would lead to defining recognition in the relevant sense as something that only takes place between persons: say, the nature as a whole cannot experience being recognized (unless it is a person, cf. animism and Gaia-hypothesis below).(Laitinen 2010).

The specific kind of two-directionality is built in very deep in experiences of getting recognition: in the very experience of getting recognition there is implicit recognition of the recognizer as recognizer. Recognition goes both ways.

Mutual recognition occurs when both A and B recognize both A and B as recognizers. The 
Hegelian tradition makes the strong claim that in inadequate cases, such as the relationship between the Master and the Slave, both A and B suffer. The claim is that everyone must be recognized for anyone to be adequately recognized (to be truly free, to be justly treated etc). ${ }^{4}$ This has been called by Raimo Tuomela (2007), the "collectivity condition": a shared goal is realized for one only if it is realized for all.

\subsection{Recognition as what?}

What we want, then, when we want recognition, is not merely being noticed, but our relevant features being adequately responded to. What are such relevant features?

Charles Taylor (1992) distinguished two kinds of features, universality and difference, and Axel Honneth three kinds of features: the universal basis of respect, particular bases of social esteem and whatever is at stake in loving care - perhaps our neediness and vulnerability or perhaps our “singularity” (Honneth 1995, Honneth 2002, Laitinen 2002).

All these come in different varieties, and the number of further distinctions needed will be relevant to the theoretical and practical context under consideration. Here is a list of ten central kinds of features that should be adequately responded to in different kinds of mutual recognition. (Compare with the list of ten forms of capabilities that Martha Nussbaum 2011 has advocated).

Universal “difference-blind” respect can concern four crucial aspects of personhood:

1) basic dignity: being the bearer of the high moral status of persons, (which is not conditional even on the degree of one's actual capacity for self-determination)

2) autonomy: the right and capacity for self-determination (which further can be subdivided into personal autonomy, moral autonomy, cognitive autonomy, - and also participation in democratic or collective self-determination which can be mentioned separately)

3) co-authorship of constituted norms (which is the same as participation in democratic or collective self-determination) $)^{5}$;

4) being an equal among others, a recipient of just and fair treatment, being a party in established egalitarian relations, being a peer in a social world, being a recipient of distributive justice. Note that this is a comparative, relational notion, a ban on second-order citizenship (See Fourie et al 2015).

Difference-sensitive esteem or regard for merits or particularities can also concern four different kinds of features (see Laitinen 2015)

5) Not being inferior to others despite having such-and-such features. This is a ban on stigmatization and discrimination. This need not be blindness to these features, but a requirement that such features that have acquired salience as "inferior" should be affirmed as "fully okay" when they are paid attention to.

6) Being a valuable contributor to the common good. Typically, having a job or other position or status where one can be assumed to contribute to society. This central to Axel Honneth's theory, which sees the unpaid contributions of housewives as a central example of lack of due recognition. ${ }^{6}$

\footnotetext{
$4 \quad$ Note that this is a highly demanding claim: is it so that adequate Mutual Recognition requires global, intergenerational justice? Why exactly would this be the case?

${ }^{5}$ Ikäheimo (2014) holds that this is what universal respect is all about.

See Ikäheimo \& Laitinen (2010) for two rival views on how to understand esteem for contributions.
} 
7) doing well in personal features and characteristics, pursuing a worthwhile personal project, having a valuable biographical identity;

8) belonging to a valuable culture or tradition; this is central to Charles Taylor's theory of politics of recognition in contexts of multiculturalism.

One can then note that parental love, or romantic love or friendship is typically neither universal, nor based on one's "merits". There are two aspects that can further be separated as relevant:

9) being a needy, vulnerable being

10) being a singled out loved one, a parent, a friend - standing in relations in which attributions and perceptions of special significance for the other are constitutive.

One can then use these different aspects in arguing for example that modern social solidarity (unlike pre-modern one) must be consistent with the relevant types of universal respect (1-4), and consists in taking turns as being a contributor (6) and recipient (9) of mutual aid, and constituting one more layer of special significance - not as thick as being a lover but being a fellow citizen (10). (Laitinen 2015).

\subsection{How does recognition require material resources? Equal, fair or sufficient shares?}

Having taken a closer look at what is at stake in recognition, we can ask whether it indeed "costs nothing”. There are direct and indirect ways in which recognition requires either sufficient, equal, or fair slices of resources.

Most directly, recognition as an equal recipient of just treatment (number 4 in the list) requires $a$ fair slice of resources. Rival theories of distributive justice will plug in different distributive principles of what fairness amounts to, and there is conceptual work to be done in figuring out how "relational" and "distributive" approaches are related, but two claims seem incontestable: being regarded as an equal in matters of justice is a central aspect of one's experience of being adequately recognized. "As an equal" must be part of the answer to the question "recognition as what?" Further, being regarded as an equal in matters of justice will require getting one's fair share of the societal resources. So, adequate recognized costs at least as much as distributive justice does. One cannot have the former without the latter. Treatment unjustly in terms of distributive justice is directly constitutive of a form of misrecognition.

More indirectly, for example being autonomous (2) arguably requires sufficient resources (similar argument could be made by appealing to life in accordance with dignity). That means that sometimes, for the rightly positioned recognizer who has the right kind of responsibility, adequately responding to someone's actual or potential capacity for self-determination means granting not only the formal rights to self-determination, but also the resources needed for the development and actualization of the capacity to self-determination. The relevant responsibility will be higher for parents, but is significant also for the whole society (and its members): sustaining practices like schooling and adequate social security.

The same consideration goes for being and becoming an able contributor to society (6), with an extra twist that if it really is a deep need that one gets to contribute to the well-being of others via work, then the society should provide meaningful job opportunities for everyone. While the experience of being unemployed can easily feel like a personal failure - not being worthy of societal esteem as one does not work and contribute to others - it can more soberly be seen as a societal failure to adequately recognize the person: giving only some the opportunity to contribute (due to structural unemployment), means to discriminate against those who do not even have the 
opportunity. Here we will start to appreciate how costly adequate recognition can be for society and its members: not only does it need to provide adequate schooling and social security, but also a nondiscriminatory system in which everyone can meaningfully contribute (via work or other arrangements).

Thirdly, as the republican tradition rightly stresses, being a citizen, a co-author or norms (3) not dominated by others, requires relatively equal resources (see Pettit 1997, Anderson 1999). This consideration is slightly different from sufficiency - what is deemed necessary for non-domination will depend on what others have. The key is to have sufficient material resources so as to be independent from pressures to yield to the arbitrary will of someone else, or be forced to work under inhuman conditions.

Finally, the recognition of needy, vulnerable beings (9) naturally brings to fore the various material needs of embodied beings, and special relationships (10) typically mean special obligations to do so. Social solidarity as responsiveness to such aspects may go beyond distributive justice strictly speaking. Merely providing the goods in a mechanistic manner is not to express genuine concern, but on the other hand, expressing genuine concern will require providing for the needs of the other if the means are at one's disposal.

All these considerations point out different ways in which limited resources might mean limited recognition, or at least, ways in which genuine recognition might have materially distributive aspects. It is no wonder, then, that recognition has come up in debates on social justice (see esp. the debate between Fraser and Honneth). It is perhaps less obvious how recognition has come to fore also in debates on environmental and ecological justice. We will now turn to these debates.

\section{Recognition in Social, Environmental, and Ecological Justice}

Three approaches to distributive justice can be distinguished by the role nature plays in them: first, social justice (incl. intergenerational, global justice), second, environmental justice (cf. also: environmental human rights), thirdly, ecological justice. Linking recognition with social, environmental, and ecological justice clarifies the connection between recognition and materialities further. We will here merely mention a possible fourth approach (e.g. Gaia-hypothesis, animism) of taking a personifying stance to nature, regarding nature more strongly a potential party to mutual recognition. What we mean by ecological justice does not require such personifying stance towards nature.

How is the lack of recognition linked with injustice in these approaches? Connecting recognition to the debates on ecological or environmental justice has far-reaching consequences: in the context of environmental justice, it can be argued that recognizing someone as an equal global citizen, one must be granted an equal slice, or fair share, of available resources and access to nature (or at least sufficiently for human capabilities needed for human dignity, and sufficiently for non-domination). In the context of ecological justice (which extends the community of justice to nonhumans) the legitimacy of these claims is further to be balanced with the legitimate claims of non-human nature and legitimate concerns for ecological limits. In this context "recognition of nature" will be relevant, even in the absence of personifying stances towards nature.

\subsection{Recognition, Social Justice, and the Instrumental Relation to Nature}

In the traditional theories of social justice, nature figures first and foremost as a (source of) resources to be divided among people: everyone ought to have their equal or fair share, or 
sufficiently for a life consistent with human dignity. In this approach, the question of natural limits appears as a challenge of scarcity: there is an incentive to overcome the limits technologically and not to waste resources. No explicit acknowledgement of any limits to technologically mediated progress in terms of material wealth is made: the implicit background assumption is that limitless growth is possible - the focus is on distribution of what has been made available.

Social justice can be broadened to cover global justice and intergenerational justice, which will mean that a society in a relatively resourceful area might not be entitled to all those resources it has landed on. People in other parts of the globe, and future generations are to be taken into consideration. (What this means will of course depend on whether the planetary limitations are acknowledged).

One more way in which the "prevalent paradigm" of justice has come to be challenged - in addition to making justice not only global, intergenerational, environmental and ecological - is posed by the “relational paradigm" of justice (Schlosberg 2007). This has taken many forms, e.g. in the so-called "relational egalitarianism," which suggests that distributive justice is not the key concern of justice, but the relations established between agents. A theory of justice may take the form not of distributive principles, but an outline of relations that would realize justice (see Honneth 2014).

We will focus on the way in which the (by definition relational) theories of recognition have figured in this: in what ways do distributive justice and recognition constitute or presuppose each other?

The relationship between recognition and distributive justice was debated by Nancy Fraser and Axel Honneth (Fraser and Honneth 2003). Fraser defended a dualist (later a trivalent) view on which material distribution and social recognition of identities and statuses are separate societal concerns. Honneth defended a monistic view that questions of distributive justice are covered by an encompassing theory of recognition.

How to assess whether dualism or monism is the better view? Both have their appeal but remain one-sided, because recognition has two aspects, which can come apart: a practical aspect, roughly that of external acts which can be assessed by the criteria of justice, and a motivational or attitudinal aspect, which is also constitutive of recognition. Monism gets right the constitutive connection, and dualism gets right the possible divergence between the aspects.

Doing whatever first-order distributive justice requires is not sufficient for adequate recognition: it must further be done for the right reason, with the right kind of motivation or attitude that sends the adequate "recognitional message". Adequate recognition requires that the reason for e.g. doing what justice requires must be that one acts simply because that is what justice and adequate treatment as equals requires. ${ }^{7}$ Yet, meeting the demands of first-order justice and equal respect is constitutive of the relations (of mutual recognition) to be established; so that responding to the normative demands is the right way to establish the relations (respecting the respectworthy, esteeming the esteemworthy; etc; for the right reasons).

In order to actualize a global order of equal respect, global distributive justice must be realized. That is very demanding (even when a merely instrumental view on nature is adopted). Suppose A is an affluent person in the west, and B works in a sweatshop in a developing country. There are wellunderstood moral demands on A: she should try not to participate in upholding the practices by not buying products made in the sweatshops, and should politically work for a world where such 
practices are eradicated, and should give to development aid sufficient amount of her income ("latitudinarian obligation”). ${ }^{8}$

Suppose B does as much as morality and justice requires of her. Yet the world is blatantly unjust. It can be argued that $A$ and $B$ have now faced tough moral luck in that fully equal interpersonal respect between $A$ and $B$ cannot be realized. It cannot be realized even though $A$ sends the right kind of recognitional message. They stand on an unequal footing nonetheless. It is a bit like A sends the message that he wants to give equal slices of the cake to each, but ends up having $99 \%$ whereas $\mathrm{B}$ gets $1 \%$. Such distributive injustice, even when it is not in the power of A to change it, means that fully equal respect cannot be realized; and that is a distinctive harm on both A and B.

\subsection{Environmental Justice and Recognition}

The notion of recognition has recently been applied to environmental and ecological justice as well. In Defining Environmental Justice, David Schlosberg (2007) argues that theories of environmental and ecological justice are incomplete if they consider justice merely as a distributional question, and suggests that the notion of recognition is apt for broadening the concerns of environmental and ecological justice. ${ }^{9}$

Environmental justice concerns the fair distribution of environmental risks or bads (from pollution to deteriorated landscapes) and environmental goods (i.e., raw materials, access to green space, and ecological services) within human-human relations. Our dependence on nature is accepted as a starting point, and overcoming it is not considered as a desirable goal. Environmental justice is best understood as a complement to social justice: it broadens the list of concerns relevant to justice. Whereas 'traditional' social justice adopts a 'resourcist' view on natural goods, environmental justice thinks about the goods and risks more broadly.

The central arguments of environmental justice can be traced back to the environmental justice movement of the people of colour in the United States. It demanded fairer environmental distribution and questioned many forms of distribution. It argued that human health cannot be traded for profit and that human exposure to harmful substances cannot be justified by appeals to economic or employment benefits (Bullard 1994): it is not just the existence or the amount of environmental resources but their quality that matters. The distribution of substitutive goods cannot compensate everything: when industrial activities pollute a lake, bringing cans of clean water to the affected people nearby simply does not amount to justice being done (Kortetmäki 2016).

Another theme linked with environmental justice is the idea of environmental human rights such as the right to an environment, that is sufficient for well-being and health (Hayward 2000). This illustrates the fundamental character of demands related to environmental goods and conditions: rights are not to be traded for some 'greater good'. They should be granted everyone, and any calculations of benefits and burdens are to take place only after these basic rights have been secured.

On latitudinarianism, see Richardson 1994.

Schlosberg's relational conception of justice contains three separate yet intertwined elements: distribution, recognition, and representation; we will focus on distribution and recognition here. Fraser has introduced similar trivalent view of justice in her theory of social justice (Fraser 2009); this is a further development from the earlier two-dimensional version of justice that comprised distribution and recognition (Fraser 1998; Fraser and Honneth 2003). 
The importance of recognition has been articulated repeatedly in the environmental movement literature. Claims for recognition are also central in the struggles of indigenous communities whose cultural traditions and practices have been ignored or disvalued in public discourse (Schlosberg and Carruthers 2010, 16). Misrecognition present in such cases is an injustice in its own right, but it is also interlinked with other elements of justice. Addressing misrecognition then helps grasp the 'why' of injustice: structural, institutional and cultural patterns that produce it (Schlosberg 2007, 12-24).

Environmental injustice and the lack of recognition often takes a collective form. This is illustrated well in the Arizona Snowbowl case (Schlosberg and Carruthers 2010). In 2002, a privately owned ski area in the San Francisco Peaks requested a permission for making artificial snow from sewage water to advance business. This was opposed by Native American tribes in the region, for whom harnessing a part of the sacred Peaks for artificial snow production would contaminate the mountain and make it 'impure'. This would thwart the prospects for maintaining traditional cultural and spiritual practices, and thereby be a form of misrecognition of tribes: their cultural traditions and values are not regarded equally important to business prospects.

Another example of environmental injustice related to misrecognition concerns global climate negotiations. This far, the most vulnerable communities such as indigenous peoples have been rendered nearly invisible in climate negotiations, in particular regarding the actual outcomes of the negotiations and strategies rather than just media visibility. Schlosberg (2012a, 452) observes that there are "understandings, social practices, norms, and ideologies that [...] do not recognize or value the cultures or peoples made most vulnerable by a changed climate" 10 .

On the other hand, climate negotiations have made the difference between the global South and the wealthier North visible: that distinction has been accentuated with struggles concerning e.g. how China should be categorized in this respect. Has the global South thereby received due recognition as a result of this visibility? Evidently not: although the status injury at stake may not be about invisibility or ignorance anymore (as the relative position of the global South has been noted in the process), due recognition of course requires that the legitimate claims of the developing countries are in fact met in the process, not merely rendered visible. One could say that the global South has been observed but not really listened to or heard. Bringing the notion of recognition into the mitigation discussion involves not only greater emission reductions but also asking more carefully how the mitigation is actually done: are the views and various lifeways of locals respected in the mitigation sites, and do local people(s) have their say over mitigation policies as well? (Hourdequin 2016).

\subsection{Recognition and Ecological Justice}

Some theorists (e.g., Baxter 2005; Schlosberg 2007) argue that there are no grounds to exclude nonhumans from the community of justice. Ecological justice significantly expands the community of the recipients of justice: it addresses human-nature relations and considers at least some nonhuman entities as proper recipients of justice. This expands the scope of justice: many ecological problems such as human-induced species extinctions and the impact of climate change

10 Schlosberg also refers to practices and ideologies that undermine the human dependence on the environment more generally. Criticizing such a denial of our material dependence on nature does not require adopting a stance of environmental justice: as we remarked earlier, even basic distributive social justice theories can acknowledge the material dependence on nature. 
on wildlife habitats become relevant topics of justice. (Schlosberg 2007, 103-159). It is vividly debated whether and what kinds of ecological objects can belong to the community of justice: some theorists argue for the inclusion of ecological systems like ecosystems while others think that only individual beings can suffer from injustice (e.g., Schlosberg 2007)

Regardless of the precise answer to the question about who are the recipients of ecological justice, such an expansion evokes the question how the nature should be treated, to be treated justly. One way to address this question relates to the recognition of nonhuman nature. In which meaning does the recognition of nature make sense, and how does that amount to nature being among the parties to be treated justly (as opposed to being something the access to which is distributed justly)?

It is a substantive ethical question what kind of value nature or natural environment possesses. In addition to instrumental value of nature, a plurality of non-instrumental values can be discerned: the value of life, its integrity or autonomy, the value of species and ecological systems, or the value individual flourishing, and so on. It is a substantive ethical question what kind of weight or priority these have for example in comparison to human well-being, freedom, relations of friendship or love, or social justice, but arguably at least some weight should be given to the non-instrumental value of nature. If this substantive view is combined with the adequate regard insight concerning recognition, it can be argued that such intrinsic valuing of nature is indeed a form of recognizing nature. Schlosberg (2007, 136-138) has proposed that the target of the recognition of nature should be its integrity, the ability to autonomous self-regulation, development, and maintenance. The adequate regard insight entails that we ought to respect these autopoietic capacities of ecological systems and nonhuman entities in a largely similar sense as we respect the autonomy of human persons.

Another approach to recognition stresses the nature of recognition as ideally mutual: only recognizers can be recognized. This rules out recognition from being applicable in ecological justice (unless we adopt some animistic worldview). Thus, to the extent that "recognition" applies to nonhuman nature, it will not be the full-fledged sort that is at stake in mutual recognition but rather a matter of adequate responsiveness to nature and its integrity. The social and institutional valuations affect our treatment of nature at large, but unlike recognizers, natural formations do not experience being misrecognized or protest out loud. Thus, the notion of recognition applies to ecological justice only with some reservations (see however the next subsection).

The crucial point here is however what ecological justice means to Sennett's slogan. Interpersonal recognition might turn out even scarcer if we take ecological justice into account (or consider the integrity of nature important even without the notion of justice): though the needs of different species and ecological systems for their existence differ, the justifiable pool of resources available to humans will be seriously limited if we take the claims of the nonhuman nature seriously. Land use is an example of this. As we have seen, sufficient, fair or relatively equal slices of resources might be required by adequate recognition, and land is needed for building shelters, producing food and acquiring other resources for human use. Such extra land might be available in the wilderness not yet touched by human habitat, but it might be out of bounds from the viewpoint of ecological justice.

\subsection{Animistic Outlooks and Recognition of Nature: A Brief Excursus}

A wholly different approach to the recognition of nature can be found in the spiritualist worldviews like the Gaian spiritual outlook and Māori cosmology that personify ecological parts of the world or 
the Earth as a whole. Animism is one dominant variant of primitive worldviews. ${ }^{11}$ We will merely mention it here as a contrast case to the kind of ecological and environmental recognition that this chapter focuses on.

The Gaian spiritual outlook on nature represents one aspect of the school of thought, the Gaia theory, that was first established by James Lovelock and Lynn Margulis. The essential core idea of the theory is that the Earth as a whole is a kind of giant, self-regulating organism. Diverging interpretations of this hypothesis have emerged since that, some of which are almost trivial whereas others are radical like the idea of a 'teleological Gaia', where the biosphere is regulated by and for the biota (Kirchner 1991). The more extreme interpretations involve the idea that essentially personifies nature and challenges the Western scientific-rational paradigms that take the physical matter of the world as mechanistic, or non-living at a minimum.

Lovelock (2000, 30-43) himself speaks of the recognition of Gaia but does so in the sense of identifying A as belonging to a particular category X (he speaks also of the recognition of a sandcastle as a human artefact). Recognizing Gaia in the adequate regard sense would mean adopting a view that in our actions, we should respect and approach Gaia as a giant organism in itself. Damaging this living organism or disrupting its self-organizing capacities in some way (through for example pollution) might constitute a case of misrecognition. Perhaps one caneven feel recognized and taken care of by Gaia - so that there would even be mutuality in the recognition.

For indigenous cosmologies similar ideas are not strange and their thinking goes even further in a direction that personifies nature. Māori cosmology involves a view that essentially personifies various ecological entities. It views rivers as living ancestors, with their own spiritual strength. Recently, the Māori people won the struggle for the recognition of The Whanganui River in New Zealand as their ancestor and a living being. Now the river has been granted legal personhood with the corresponding rights and duties (Hutchison 2014). It is an interesting question how the status of The Whanganui River should be approached in terms of recognition. Granting legal statuses is itself a form of recognition. Legal treatment clearly implies an assumption of some kind of mutuality: the river has both rights and duties, and the view that river is an ancestor also means that it is essentially similar to people in at least some spiritual sense. The river is regarded as an agent: some events are its doings. If so, it might conceivably have e.g. a duty to refrain from inappropriate actions; and in treating presently living humans appropriately, it can in principle be interpreted as reciprocating adequate regard towards humans. Further research on how in fact the Māori people understand this mutuality and these duties would be required to better understand this relationship with nature. In any case, the status of the Whanganui River appears to represent the strongest form of the recognition of nature present in the world as we know it.

In a world with diverse relationships to nature, we can also study whether different communities' or peoples' or tribes' views about nature are adequately recognized. In granting the Whanganui River the status of a legal person, the legal system of New Zealand gives recognition to the values and worldview of the Māori people. There can be three kinds of recognition going on simultaneously: even if the legal system treats the river only "as if" it is a person, it nonetheless respects the tribe's

\footnotetext{
${ }^{11}$ Anthropologists have often remarked the Amazonian tendency to 'treat certain elements in the environment as persons endowed with cognitive, moral and social qualities analogous to those of human' (Descola 2013, 31). Thus, in addition to humans, the category of persons can include 'spirits, plants, and animals' (ibid.). The Anthropologist Philippe Descola $(2013,122)$ argues that such animism in one of the four basic ways to understand how humans differ from the rest of nature, the others being naturalism, totemism and analogism.
} 
rights to formulate a worldview of their own. It possibly also esteems or gives positive value or recognizes the differential worth of the view in question (but not necessarily: see e.g. Taylor 1992, Jones 2006, Laitinen 2006.).

\section{Planetary Limits}

\subsection{Scarcity, Unsustainability, and Future Generations}

Our discussion has focused mainly on the present-day humans. Environmental justice and even some accounts of social justice, however, require taking the future generations into account: doing justice to current generations by "borrowing from the future" is unjustifiable. Thus, sustainability becomes an additional condition for global justice. The concern for both present and future humans, when linked with the problems of scarcity and unsustainability, constitutes a challenge that can be termed the natural or planetary limits of recognition.

The problem of scarcity is here relevant insofar as it concerns natural goods (resources or ecosystem services) that are necessary for a decent human life. Scarcity means that those goods cannot be provided for everyone to the extent required by equal recognition, or that their provision needs to be done at the cost of some other crucial good: metaphorically, the cake may be too small for giving everyone a decent slice. Scarcity with respect to basic necessities constitutes a pressing dilemma for the theories of social justice and recognition. Assuming that the cake is too small, should we give just equal yet indecent crumbles to everyone or try to get as many as possible above the decency threshold? Getting around the problem with short-term fixes may be possible but unsustainable: justice to present humans would mean injustice for future generations.

To determine how serious the problem of scarcity will be, there should be a view on how big slices a decent human life and equal recognition requires. What standard of living would be decent and consistent with human dignity, and could it be provided sustainably? Evidently, the average Western standard of living must go. If everyone lived like let us say an average Finn, the whole humanity would need four Earths to meet its material needs. ${ }^{12}$ Worse, a study on minimum income receivers in Finland found out that the ecological footprint of even the poorest Finns exceeded sustainable resource use, with the exception of a homeless person (Hirvilammi et al., 2013). This indicates that prospects for the equal and sustainable recognition of all persons seem weak under current post-industrial forms of life, at least in the countries where even having an adequate shelter involves high energy consumption. One solution could be to migrate people to more favourable conditions where decent lives require less resources. But a forced mass migration is hardly justifiable from the viewpoint of recognition, and it can be doubted whether more favourable locations could sustain increased population in the long run. Another solution to the scarcity problem could be a radical change in the patterns of production and consumption, which would likely require a significant change in the capitalist economic system or even abandoning it.

The global greenhouse gas emissions and the carbon requirements of a decent human life are another case in point. Current per capita carbon emissions are roughly 3 t/a in industrialized countries. If the global population reaches 10 billion, (likely) avoiding dangerous climate change would require average per capita emissions to be reduced to 0.3 t/a by $2100 .{ }^{13}$ Much could of course be done by switching to renewable energy, reducing the red meat and rice production, and

12 This estimate is based on the ecological footprint data available at Global Footprint Network (http://www.footprintnetwork.org/).

13 http://www.ipcc.ch/ipccreports/tar/wg3/index.php?idp=57 
fundamentally changing the transportation and fuel infrastructure - but the difference in numbers is huge, and progress has this far been minor. It appears that the humanity is at great risk of exceeding the natural limits of recognition, or might have done so already, in terms of environmental justice granting all people the access to a stable atmosphere and the natural resources whose production or renewal requires such atmospheric stability.

\subsection{Planetary Boundaries}

The planetary boundaries framework provides a useful approach to the limits of recognition that relate to scarcity and unsustainability. Humanity's total impact on the Earth has borders that should not be exceeded in the long run. Those borders are formed by the natural limits of resource availability, ecosystem services, and the renewal rate of resources as well as the capacity of natural cycles (like nutrient cycles) to maintain themselves. This idea of a safe operative space for the humanity has been conceptualised by the planetary boundaries approach that defines the safe operating space for humanity if we want to avoid major human-induced global environmental changes (Steffen et al. 2009). Such changes - including but not limited to dangerous climate change or freshwater availability collapse - can undermine the material conditions of human well-being and, as we argue, make the equal recognition of all persons impossible. These limits can be called the natural limits of recognition. From the overall nine environmental variables that are called planetary boundaries, it is estimated that humanity has already transgressed the safety limit of four: climate change, biosphere integrity, biogeochemical flows, and land system change (Steffen et al. 2009).

The problem is further worsened by population growth. At present, the global population is approximately 7.5 billion and still increasing. The aggregate human impact on the Earth is the product of global population and the average ecological impact of a person. Unless global population or the average ecological impact per capita begins to decrease (both seem unlikely in the near future), there is an increasing pressure towards the boundaries of safe operating space for humanity. Global population growth inevitably makes the equal recognition of all humans an increasingly difficult task.

\subsection{Ecological Justice and Planetary Limits}

As we have seen, ecological justice requires that nonhuman nature should be granted recognition as well. This requires respect for nature's autonomy and integrity that allows the realization of potential in nature (Schlosberg 2007, 131-142). Taking this view into account has radical impacts on the natural limits of recognition.

Non-human entities are biological creatures just like humans, and their well-being has a material dimension likewise. Recognition of nature, then, involves a material dimension. This worsens the problem of scarcity: the community of justice expands significantly but the amount of available natural goods does not. ${ }^{14} \mathrm{~A}$ decent life of many species of non-humans is likely to have very modest requirements in comparison to human needs, but this does not solve the problem. Resources appropriated for human use are usually not available for non-humans anymore. It is possible to keep

14 Actually, the size of the cake does increase slightly, or perhaps we should speak of multiple cakes: there are natural goods that are of no use for humans but necessary for other organisms: consider decayed plant material or inedible mushrooms. Many of the goods however are crucial for both humans and other organisms, or the human way to use them prevents other uses (consider the lands transformed into monocultural plant cultivation). 
some public goods such as clean air and freshwater supplies equally available for both humans and non-humans, but in the case of distributable resources the problem of scarcity (that existed even without the consideration of nonhuman needs) worsens. Ecological justice would require that a significant part of the 'cake' should be left to non-humans, and this unavoidably reduces the cake available for promoting social justice.

\section{Conclusion}

This chapter has examined the intertwinement of social recognition with material preconditions and ecological, planetary limits. Contrary to Sennett's Slogan, recognition is at least as hard to achieve as social justice, because just treatment is one constituent in adequate recognition. Broadening the scope of social justice and recognition to intergenerational and global questions, and to environmental and ecological justice makes the question even harder. In circumstances, where systematic injustice prevails, we each suffer from not being able to pass the "eyeball test" of being able to look everyone in the eyes as an equal - we suffer from not being in a position of adequate mutual recognition.

\section{Bibliography}

Anderson, E. (1999) What Is the Point of Equality? Ethics 109(2), 287-337.

Baxter, B. (2005) A Theory of Ecological Justice. London: Routledge.

Broome, J. (1990) Fairness. In Proceedings of the Aristotelian Society 91, pp. 87-101. Aristotelian Society, Wiley.

Bullard, R. (ed.) (1994) Unequal Protection: Environmental Justice and Communities of Color. San Francisco: Sierra Club Books.

Deranty, J-P. (2009) Beyond Communication: A Critical Study on Axel Honneth's Social Philosophy. Boston: Brill.

Descola, P. (2013) Beyond Nature and Culture. Chicago: University of Chicago Press.

Fitzgerald, D. (2013) Philippe Descola’s Beyond Nature and Culture. Somatosphere. Available online: http://somatosphere.net/2013/10/philippe-descolas-beyond-nature-and-culture.html (Accessed 30 August 2017.)

Fourie, C.; Schuppert, F. and Wallimann-Helmer, I. (eds.), (2015) Social Equality: On What It Means to Be Equals, Oxford: Oxford University Press.

Fraser, N. and Honneth, A. (2003) Redistribution or recognition? A political-philosophical exchange. London: Verso.

Fraser, N. (1998) Social Justice in the Age of Identity Politics: Redistribution, Recognition, and Participation, in The Tanner Lectures on Human Values, vol. 19. Salt Lake City, UT: University of Utah Press.

Fraser, N. (2009) Scales of justice: reimagining political space in a globalizing world. New York, Columbia University Press. 
Hayward, T. (2000) Constitutional Environmental Rights: a Case for Political Analysis. Political Studies 48(3): 558-572.

Hegel, G.W.F (1977 [1807]) Phenomenology of Spirit, Oxford: Oxford University Press.

Hirvilammi, T., Laakso, S., Lettenmeier, M. \& Lähteenoja, S. (2013). Studying Well-being and Its Environmental Impacts: A Case Study of Minimum Income Receivers in Finland. Journal of Human Development and Capabilities 14(1): 134-154.

Honneth, A. (1995) Struggle for Recognition: The Moral Grammar of Social Conflicts. The MIT Press.

Honneth, A. (2010) The I in We: Studies in the Theory of Recognition. Cambridge: Polity Press.

Honneth, A. (2014) Freedom's Right: The Social Foundations of Democratic Life, Cambridge: Polity Press.

Hourdequin, M. (2016) Justice, Recognition, and Climate Geoengineering. In Christopher Preston, ed. Climate Justice and Geoengineering: Ethics and Policy in the Atmospheric Anthropocene, Rowman \& Littlefield.

Hutchison, A. (2014). The Whanganui River as a Legal Person. Alternative Law Journal 39(3), 179-182.

Ikäheimo, H. (2002) On the Genus and Species of Recognition, Inquiry, 45:4, 447-462.

Ikäheimo, H. (2014) Anerkennung. Berlin, New York: De Gruyter.

Ikäheimo, H. \& Laitinen, A. (2007) Analyzing Recognition: Identification, Acknowledgement and Recognitive Attitudes Towards Persons, in Bert van den Brink \& David Owen (eds.) Recognition and Power. New York: Cambridge UP, 33-56

Kirchner, J.W., 1991, The Gaia hypotheses: Are they testable? Are they useful? In S.H. Schneider and P.J. Boston (Eds.) Scientists on Gaia (Cambridge, MA: MIT Press), pp. 38-46.

Kortetmäki, T. (2016) Is broad the new deep in environmental ethics? A Comparison of Broad Ecological Justice and Deep Ecology. Ethics \& the Environment 1(2016), 89-108.

Laitinen, A. (2002) Interpersonal recognition: a response to value or a precondition of personhood? Inquiry 45:4, 463-478.

Laitinen, A. (2009) Recognition, Needs and Wrongness: Two Approaches. European Journal of Political Theory 8(1): 13-30.

Laitinen, A. (2010) On the scope of recognition: The Role of Adequate Regard and Mutuality. In Schmidt am Busch \& Zurn (eds.), The Philosophy of Recognition. Lanham: Lexington, pp. 319342. 
Laitinen, A. (2015) Recognition, Solidarity, and the Politics of Esteem: The Case of Basic Income in Recognition and Freedom: Axel Honneth's Political Thought, eds. Odin Lysaker and Jonas Jacobsen, Brill, Social and Critical Theory 17; 57-78.

Lovelock, James. (2000). Gaia: A New Look at Life on Earth. Oxford: Oxford University Press.

Nussbaum, M. (2011) Creating capabilities. Cambridge, Mass: Harvard University Press.

O’Neill, J. (ed.) (1996) Hegel's Dialectic of Desire and Recognition: Text and Commentary. Albany: State University of New York Press.

Patterson, O. (1982) Slavery and Social Death. Cambridge, Mass: Harvard University Press.

Pettit, P. (1997) Republicanism: A Theory of Freedom and Government. Oxford: Oxford University Press.

Rauschmayer, F. \& Lessmann, O. (2013) The Capability Approach and Sustainability. Journal of Human Development and Capabilities 14(1): 1-5.

Richardson, H. (1994). Practical Reasoning About Final Ends. Cambridge: Cambridge University Press.

Ricoeur, P. (2005) The Course of Recognition. Cambridge, Mass.: Harvard University Press.

Sen, A. (1992) Inequality Re-examined. Oxford: Clarendon Press.

Scanlon, T. (1998) What We Owe to Each Other. Cambridge, Mass.: Harvard University Press.

Schlosberg, D. (2007) Defining Environmental Justice: Theories, Movements, and Nature. Oxford: Oxford University Press.

Schlosberg, D. (2012a) Climate Justice and Capabilities: A Framework for Adaptation Policy. Ethics \& International Affairs, 26(4): 445-461. doi:10.3197/096327106778226293

Schlosberg, D. (2012b) Justice, Ecological Integrity, and Climate Change. In Thompson, Allen, and Bendik-Keymer, Jeremy, eds. Ethical Adaptation to Climate Change. Cambridge: MIT Press.

Schlosberg, D., Carruthers, D. (2010) Indigenous Struggles, Environmental Justice, and Community Capabilities. Global Environmental Politics 10(4), 12-35.

Spengler, L. (2016) Two Types of ‘Enough’: Sufficiency as Minimum and Maximum. Environmental Politics 25(5): 921-940.

Steffen, W., et al (2015) Planetary Boundaries: Guiding Human Development on a Changing Planet. Science 347: 6223,1259855.

Testa, I. (2009) Second Nature and Recognition: Hegel and the Social Space. Critical Horizons 10(3): 341-370.

Tuomela, R. (2007) Philosophy of Sociality, Oxford: Oxford University Press. 
Wilkinson, David M. (2015) On Gaia: a Critical Investigation of the Relationship between Life and Earth. International Journal of Environmental Studies 72(4), 724-730. 